\title{
O desabafo de Beto Richa nas redes sociais: uma análise do ethos discursivo
}

\author{
João Thiago Monezi Paulino da Silva \\ Universidade Federal de São Carlos (UFSCar), São Carlos, São Paulo, Brasil \\ joaothiago79@yahoo.com.br
}

DOI: http://dx.doi.org/10.21165/el.v46i3.1615

\section{Resumo}

Este artigo analisa o ethos discursivo de uma publicação posta em circulação na fanpage de Beto Richa, governador do Estado do Paraná, na rede social Facebook. Para dar conta desse objeto, a pesquisa ancora-se nos pressupostos teórico-metodológicos da Análise do Discurso de orientação francesa, sobretudo nos postulados de Dominique Maingueneau $(2005,2008,2010)$ sobre o modo de construção do ethos discursivo. O objetivo é descrever de que maneira determinadas instâncias subjetivas se configuram no jogo enunciativo entre locutores, verificando, nesse processo, a formulação de sentidos correspondentes à figura representativa do governador Beto Richa.

Palavras-chave: ethos discursivo; fanpage; Beto Richa; instâncias enunciativas.

\section{The outflow of Beto Richa in social networks: an analysis of the discursive ethos}

\begin{abstract}
This paper analyze the discursive ethos of a publication disseminated in the fanpage of Beto Richa, the Paraná state governor, in the social network Facebook. To realize this object, the research is anchored in the theoretical and methodological assumptions of the French orientation of Discourse Analysis, especially in the postulates of Dominique Maingueneau (2006, 2008, 2010) on the method of construction of the discursive ethos. The aim is to describe how certain subjective instances are configured in the enunciation game between speakers, by checking in the process the formulation of meanings corresponding to the representative figure of the governor Beto Richa.
\end{abstract}

Keywords: discursive ethos; fanpage; Beto Richa; enunciative instances.

\section{Considerações iniciais}

A partir da popularização da internet, em meados dos anos 1980, os meios de comunicação tiveram possibilidade de promover, ainda mais, a difusão da informação, da cultura e do entretenimento. Em cada país, esse processo de propagação da informação se deu de forma peculiar. No Brasil, houve crescimento e popularização das chamadas redes sociais, as quais procuram ter um propósito de compartilhamento de interesses comuns entre indivíduos de uma mesma comunidade.

No caso da política, um exemplo dessas redes sociais utilizadas é o Facebook. Trata-se de uma plataforma de relacionamento cujo número de usuários que a acessaram no último trimestre de 2014 chegou a 92 milhões (IBGE, 2014). Tamanha transmissão de informações faz do Facebook um dos lugares mais significativos quando se pretende 
difundir uma ideia, uma marca ou um produto. Desse modo, cada vez mais, os políticos utilizam-se das chamadas fanpages ${ }^{1}$ para manutenção de sua imagem.

No estado do Paraná, no dia 29 de abril de 2015, houve um protesto contra o projeto de lei que pretendia suprimir direitos previdenciários, no qual, segundo a prefeitura de Curitiba, 213 pessoas ficaram feridas. Neste artigo, toma-se como objeto de estudo o pronunciamento do então governador do Estado do Paraná, Beto Richa, publicado em sua fanpage oficial, lamentando o incidente com os servidores.

O texto em análise foi retirado do site da revista Época ${ }^{2}$, visto que, alguns dias depois da publicação, os administradores da fanpage oficial do governador retiraram seu pronunciamento do ar. A eleição desse texto, para os estudos discursivos, se deve à percepção de uma mobilização de um ethos, por parte do autor do texto, em favor da manutenção de sua reputação na política.

Para dar conta desse objeto, a pesquisa ancora-se nos pressupostos teóricometodológicos da Análise do Discurso de orientação francesa, sobretudo nos postulados de Maingueneau $(2006,2008,2010)$ sobre a construção do ethos discursivo. O objetivo é descrever de que maneira determinadas instâncias subjetivas se configuram no jogo enunciativo entre locutores, verificando, nesse processo, a formulação de sentidos correspondentes à figura representativa do governador Beto Richa.

Para os estudos do discurso, a pesquisa poderá contribuir para a compreensão do papel das ferramentas tecnológicas como meio de representação política na nossa sociedade. Em vista disso, considerando o discurso no bojo de um interdiscurso (MAINGUENEAU, 2005), as análises também pretendem pôr em evidência de que maneira as redes sociais, ligadas à internet, funcionam como mediadoras de discursos na construção de um ethos discursivo político.

\section{As redes sociais - O Facebook}

Há muitos anos existem redes sociais. O ser humano sempre viveu em relacionamentos dentro de comunidades, sejam elas constituídas por laços familiares, religiosos, etc. No entanto, é a partir da criação de sites de redes sociais em ambientes virtuais, nos anos 1990, com a popularização da internet, que elas se tornaram cada vez mais presentes na vida das pessoas.

De um lado, as redes sociais ampliaram a interação humana por meio de diferentes suportes midiáticos virtuais. Por outro, no campo dos estudos do discurso, propiciaram outros olhares sobre o texto publicado nos ambientes virtuais. Para Maingueneau (2010), esses olhares tratam desde questões ligadas à noção de autoria quanto à construção dos ethé, particularmente sobre os que se referem ao campo político.

No Brasil, o mais famoso site de redes sociais e mais acessado é o Facebook ${ }^{3}$. O caráter interativo de comunicação do Facebook, para Silva (2012), produz um imaginário

\footnotetext{
${ }^{1}$ Segundo o Facebook, uma fanpage é uma interface específica para a divulgação de uma empresa, marca, banda, etc. Disponível em: $<$ http://fanpages.com.br/fan-page.html $>$.

${ }^{2}$ Texto disponível no site: $<$ http://epoca.globo.com/tempo/filtro/noticia/2015/05/o-desabafo-de-beto-richanas-redes-sociais 1.html>.

${ }^{3}$ Criado por Mark Zuckerberg, Chris Hughes, Eduardo Saverin e Dustin Moskovitz, a rede social foi baseada no Facemash, idealizado por Zuckerberg em outubro de 2003 para que os estudantes de Harvard onde ele cursava o segundo ano - pudessem escolher os amigos mais atraentes. Disponível em:
} 
de acesso à informação. Isto é, o usuário tem a impressão de que está sempre conectado e disposto a receber informações em tempo imediato. No caso dos textos publicados em perfis de figuras políticas no Facebook, há um terreno fértil para a construção do ethos, uma vez que essas páginas são alimentadas constantemente com textos que carregam mecanismos de autopromoção da figura política, incluindo menção a partidos políticos aos quais estes estão afiliados.

Sobre as publicações de textos na internet, Maingueneau (2010, p. 40) afirma que

O acesso à "publicação" não é mais limitado por intermediários. [...]. A proliferação de produtores e o desaparecimento dos intermediários tornam improvável o destaque de figuras proeminentes: assiste-se a uma confrontação direta entre uma oferta virtualmente ilimitada e leitores aleatórios surgidos de uma multidão insondável.

O que se percebe, portanto, nos textos publicados em perfis de políticos no Facebook é um contínuo de publicações em torno da carreira política e das atividades diárias das quais o político participa. Essa quantidade de publicações diárias, de certa maneira, passa por intermediários, no caso, os assessores de comunicação.

Dessa maneira, há uma construção de textos que levam a uma interpretação voltada à adesão do público-leitor (usuário que, por ventura, "curtiu"4 tal figura política) às ideologias partidárias ligadas à figura do político. Com propósitos ideológicos, as publicações procuram estabelecer uma relação imaginária de cumplicidade e participação ativa entre uma "oferta virtualmente ilimitada e leitores aleatórios surgidos de uma multidão insondável", como afirma Maingueneau (2010), no excerto acima citado.

De fato, a relação entre a figura política e o seu interlocutor demarca um posicionamento conflituoso quanto à estabilidade daquilo que é publicado. Desse ponto de vista, Maingueneau (2010) considera que a apresentação desses textos é modificada a todo o momento, de modo que se torna impossível afirmar que um texto publicado esteja em sua versão final.

Essa instabilidade dos textos publicados na internet leva a um modo de composição particular do gênero discursivo publicado em perfis de figuras políticas. Pelo caráter composicional desses textos, estariam ligados a uma multimodalidade (MAINGUENEAU, 2010), isto é, produziriam sentido juntamente com o verbal, o dito, e com outras imagens que compõem o gênero discursivo.

\section{Sobre o ethos discursivo}

A noção de ethos discursivo, elaborada por Maingueneau a partir dos anos 1980, consiste em um deslocamento do conceito de ethos retórico, proposto por Aristóteles. Amossy (2011, p. 10) caracteriza esse ethos aristotélico como a "construção de uma imagem de si destinada a garantir o sucesso do empreendimento oratório".

\footnotetext{
$<$ http://tecnologia.terra.com.br/facebook-completa-10-anos-conheca-a-historia-da-redesocial,c862b236f78f3410VgnVCM20000099cceb0aRCRD.html>.

${ }^{4}$ Clicar em "Curtir" em uma publicação no Facebook é um modo fácil de dizer às pessoas que você gostou, sem deixar comentários. Disponível em: <https:/www.facebook.com/help/110920455663362>. Acesso em: 14 jul. 2017.
} 
No entanto, discursivamente, Maingueneau (2010, p. 79), pensando o ethos não somente na imagem que o orador procura construir de si mesmo para persuadir seu interlocutor, mas como um processo coextensivo a toda enunciação, propõe uma noção de ethos discursivo: "o destinatário é necessariamente levado a construir uma representação do locutor, que este último tenta controlar, mais ou menos conscientemente e de maneira bastante variável, segundo os gêneros do discurso". Nesse sentido, podemos compreender que a noção de ethos, proposta por Maingueneau, está também na ordem do discurso, isto é, na relação enunciativa entre locutor e destinatário, e não somente em um posicionamento empírico entre eles.

Diferentemente da pragmática de Ducrot (1987), que caracterizava o ethos como a distinção entre "locutor-L" (enunciador) e "locutor-lambda" (ser empírico no mundo), Maingueneau entende o sujeito como uma instância subjetiva, imersa em condições sócio-históricas e atravessada por estereótipos que determinam, sobretudo, um modo de ser. Essa instância subjetiva, para Baronas (2011, p. 53), "não pode ser concebida como uma simples perspectiva enunciativa, na qual o sujeito conscientemente se desloca e passa a falar de diferentes posições enunciativas, mas como uma 'voz' associada a um 'corpo enunciante' historicamente determinado".

Assim, o ethos discursivo, na compreensão de Maingueneau (2010, p. 80), implica um "mundo ético", num certo posicionamento discursivo no qual a instância subjetiva se inscreve. O ethos é construído no âmbito da atividade discursiva (MAINGUENEAU, 2005).

Para Maingueneau (2008, p. 64), nessa concepção de ethos, há, na atividade discursiva, uma "vocalidade", um "fiador", que atesta o que é dito por meio do seu "tom". Cabe ao destinatário identificar e avaliá-lo positiva ou negativamente, apoiando-se num conjunto difuso de representações. O fiador, nesse sentido, é um elemento importante da cena enunciativa, pois procura validar, por meio de traços éticos e estereótipos com os quais o destinatário pode vir a se identificar.

Maingueneau (2008, p. 71) afirma que ele resulta de uma interação de diversos fatores: "ethos pré-discursivo, ethos discursivo (ethos mostrado), mas também de fragmentos de texto em que o enunciador evoca sua própria enunciação (ethos dito)". Para o autor, portanto, o ethos discursivo é da ordem da enunciação, isto é, por meio da fala ou da escrita, numa dada conjuntura, o fiador diz de si mesmo (ethos dito) e/ou deixa marcas enunciativas no texto (ethos mostrado), que fazem o destinatário construir uma identidade com aquilo que se pressupõe um mundo ético para ele.

\section{Notas sobre o corpus}

Antes de tratarmos do ethos discursivo do texto em análise, tomemos, para efeito de gestão do contexto, uma descrição da fanpage do governador Beto Richa na qual o texto foi publicado.

Todos os posts estão relacionados às atividades diárias do governador. Dentre elas, podemos citar informações sobre economia, agropecuária, saúde, educação, segurança, etc. Cada post é sempre acompanhado de uma imagem, que pretende criar efeito de legitimação e presentificação de tal atividade política. $\mathrm{O}$ assunto dos posts, em sua maioria, relaciona-se a tratados do governo com entidades, acordos fechados com grandes empresas, construção de rodovias, situação das indústrias no Estado, entre outros. 
Esse modo de operacionalização da fanpage demonstra traços característicos de um gênero discursivo que pode vir a comportar uma "cenografia digital", conforme Maingueneau (2015) classifica a cenografia dos gêneros postos em circulação na web. Isso implica um modo de olhar para o gênero discursivo além de sua natureza, isto é, para além de um dispositivo de comunicação sócio-historicamente condicionado. Essa cenografia digital pode ser analisada sob um componente iconotextual, um componente arquitetural e um componente procedural ${ }^{5}$. (MAINGUENEAU, 2015).

A cenografia digital da fanpage do governador Beto Richa (PSDB) pode ser vista como um espaço em que diferentes textualidades e novas formas de genericidade convergem para a construção do ethos. Nesse espaço, a maneira como os textos são publicados, em forma de diários, procura, de saída, caracterizar uma relação de intimidade com os destinatários, que podem ser os internautas que "curtiram" a fanpage, os eleitores adeptos à corrente partidária na qual o governador do estado do Paraná está afiliado ou ainda aqueles eleitores de oposição partidária.

Para conhecimento do texto publicado na fanpage do governador, segue-o, abaixo, na íntegra ${ }^{6}$ :

O silêncio que guardei nos últimos dias serviu para uma reflexão profunda sobre os acontecimentos do dia 29 de abril, na Praça Nossa Senhora de Salete, em Curitiba. Desde então, adotamos uma série de medidas, que incluiu a troca de secretários e mudanças na legislação.

Entretanto, tenho consciência que nada apagará da minha alma a tristeza que sinto com este episódio, lamentável sob todos os lados. Não pouparei esforços para restabelecer o diálogo com os servidores e com a sociedade paranaense, porque é nisso que eu acredito, no entendimento, na busca do bem comum.

Toda e qualquer forma de violência deve ser repudiada. Sofro com isso mais do que você possa imaginar. Quem me conhece sabe que sempre fui uma pessoa acessível, aberta, uma pessoa do diálogo.

A verdade é que o confronto nunca é desejável. Principalmente para quem, como eu, cultiva valores éticos e cristãos. Sempre acreditei que o respeito às ideias divergentes é um dos pilares da democracia e não posso concordar jamais com atitudes que coloquem em risco a vida de alguém. Venha de onde vier, a violência e a intolerância são sempre condenáveis.

Ao contrário do que alguns tentaram dizer à população, as mudanças na Paraná Previdência não retiram nenhum direito dos servidores públicos. O Estado também não vai sacar os recursos lá depositados, que só podem ser usados para o pagamento de aposentados e pensionistas.

\footnotetext{
${ }^{5}$ Sobre o funcionamento desses componentes, ver: MAINGUENEAU, Dominique. Discurso e Análise do Discurso. Tradução de Sírio Possenti. São Paulo: Parábola Editorial, 2015.

${ }^{6}$ Texto coletado na reportagem da revista Época, cujo título é "Quase dez dias após manifestação de professores, governador pede a 'compreensão' da população”. Ele foi publicado no dia 08/05/2015, tanto no site da revista quanto na fanpage do governador Beto Richa.
} 
O que houve foi apenas uma alteração no plano de custeio de aposentados e pensionistas. E o Estado do Paraná continua sendo o responsável maior pelo pagamento desses benefícios.

Para que você tenha uma ideia, mesmo com a mudança, o Estado vai continuar gastando R \$ 380 milhões por mês com o pagamento de 106 mil aposentados e pensionistas. Já a contribuição dos servidores continuará sendo de R $\$ 75$ milhões por mês.

O nosso maior compromisso é com todos os paranaenses, que esperam mais investimentos em serviços essenciais, como saúde, educação e segurança, em obras de infraestrutura vitais para o crescimento econômico e a geração de novos empregos.

Por tudo isso, peço humildemente a sua compreensão. O Paraná precisa do esforço e do compromisso de cada um de nós para seguir adiante. Vamos virar a página do "quanto pior, melhor". Vamos acreditar que as crises podem e devem ser superadas. Com trabalho, determinação e verdade. Toda a estrutura do Governo está mobilizada para alcançar os resultados que o Estado precisa e merece.

Para compreender o modo de construção do ethos nesse texto, é necessário contextualizar o modo da fala do discurso político para, depois, o relacionarmos com a posição partidária a qual Beto Richa está afiliado. Sobre a fala do discurso político, Charaudeau (2007, p. 246) afirma que:

A fala do discurso político é uma fala que, de um lado, circula no espaço público e, de outro, se inscreve em uma cena política. [...] Uma fala que circula no espaço público é uma fala que é lançada sem que se tenha o total domínio dos efeitos que ela produzirá, mas com a suposição racional de que ela será interpretada de diferentes maneiras.

Cabe pensar no modo como essa fala, inserida num certo funcionamento enunciativo de uma fanpage, produz efeitos na construção do ethos. O espaço público, relacionado à fanpage, produz uma cenografia diferente da de outro lugar de atividade discursiva, como um palanque ou um programa televisivo, por exemplo. Nesse espaço da $w e b$, o texto publicado pelo governador é, em certo modo, regulado por filtros do site (Facebook) em que se hospeda a fanpage, mas, ao mesmo tempo, quando é posto no ambiente virtual, perde o total domínio daquilo que se diz, bem como os efeitos e suas interpretações. Percebe-se, desse modo, uma instância subjetiva pertencente a uma cena política que busca controlar aquilo que é dito. Charaudeau (2007, p. 247) relaciona a cena política a uma instância de poder:

A cena política se caracteriza por um dispositivo que é posto a serviço de uma expectativa de poder. Esta última coloca em presença uma instância política e uma instância cidadã. A instância política está toda direcionada a um "agir sobre o outro" que deve ser acompanhado de uma "exigência de submissão do outro", o que explica que essa tensão seja orientada em direção à produção de efeitos.

Assim, podemos, de antemão, pensar no posicionamento da instância subjetiva política em vias de legitimar um lugar de dominação e poder sobre o outro. A publicação diária dos textos vinculados à figura de Beto Richa nas redes sociais é uma forma de dar manutenção à imagem de uma instância mais cidadã, mas, ao mesmo tempo, procura manipular o discurso do outro e gerenciar positivamente o seu ethos. 
Discursivamente, é possível perceber no texto, de acordo com o quadro explicitado acima, três planos distintos de ethos: o pré-discursivo, o dito e o mostrado. Os planos procuram manter uma relação de cumplicidade da instância subjetiva da figura de Beto Richa em vista de construir uma imagem de vítima do ocorrido no dia 29 de abril, no Paraná.

\section{O ethos pré-discursivo}

Há uma incorporação por parte do leitor sobre o ethos pré-discursivo de Beto Richa. A imagem estereotipada é construída em torno da história da família Richa na política do Estado do Paraná. O pai de Beto Richa, José Richa, foi prefeito de Londrina PR, entre 1973 e 1977, e governador do estado do Paraná, entre os anos de 1983 e 1986. Em suas passagens como prefeito e governador, José Richa obteve êxito administrativo. Isso implica uma possível construção de valores identitários que ultrapassam a figura do fiador do texto.

Ativa-se, desse modo, já no início da leitura do diário, um "mundo ético" (MAINGUENEAU, 2008, p. 65) no qual o leitor tem acesso a um conjunto de situações estereotípicas associadas ao comportamento administrativo de José Richa. Quando, no início do texto, o locutor enuncia, de saída, "O silêncio que guardei nos últimos dias...", implica uma manobra política que procura demonstrar um comportamento do locutor com intuito de sociabilizar uma comoção com o acontecimento do dia 29 de abril.

Diante disso, a instância discursiva articula o seu posicionamento a uma "voz" historicamente associada, no caso, a figura de José Richa, visto que demonstrou, nos períodos em que governou Londrina e o Estado do Paraná, um posicionamento reflexivo diante dos fatos de sua administração. O discurso, portanto, mostra-se num tom confessional, isto é, o locutor se coloca numa condição de humilhação e tristeza perante o episódio. Isso pode demonstrar um ethos complacente, suscetível de atingir um público amplo e variado, como é o caso da web e, particularmente, das redes sociais.

\section{O ethos discursivo - dito}

Maingueneau (2008) afirma que a adesão do destinatário opera-se por um apoio recíproco da cena da enunciação. Nesse sentido, o ethos é parte pregnante do discurso, uma vez que o enunciado está associado a um discurso, a um gênero e a um construto no seu próprio modo de operacionalização.

Discursivamente, é possível descrever, em todo momento da enunciação, uma instância subjetiva preocupada com a apresentação de si. Esse processo apresenta relação com o ethos dito. Para Maingueneau (2010, p. 83), o enunciador "pode, de fato, dar informações sobre si mesmo que contribuirão para ativar certo ethos não discursivo, que o leitor confrontará com o ethos discursivo".

Segmentos discursivos, como "porque é nisso que eu acredito, no entendimento, na busca do bem comum", "Quem me conhece sabe que sempre fui uma pessoa acessível, aberta, uma pessoa do diálogo" e "Principalmente para quem, como eu, cultiva valores éticos e cristãos.”, tratam de informações de ordem psicológica do locutor.

Vale ressaltar valores e crenças compartilhados por uma determinada comunidade: "no entendimento", "pessoa do diálogo", "valores éticos e cristãos" constroem estereótipos de mundos éticos que incluam tais comportamentos do locutor, 
indissociáveis ao mundo contemporâneo (todos precisam ser tolerantes, todos precisam ser bons, todos precisam ser pessoas acessíveis).

Essas informações levam o leitor do texto a ativar mundos éticos com os quais ele se identifica. Essa estratégia de benevolência, que se constrói por meio do ethos dito, visa estabelecer uma espécie de preparação para aquilo que o locutor pretende inferir em seu discurso. O modo de representatividade política da figura do governador Beto Richa está vinculado, no Estado do Paraná, à instância do $\mathrm{PSDB}^{7}$. Desse modo, caso o leitor seja adepto a este partido político, é direcionado a construir, pela maneira como o ethos dito é posto na cena, certas cumplicidade e compaixão pela situação de confronto na qual o governador foi posto. Do contrário, leva o leitor da oposição a refletir sobre um possível arrependimento do governador diante do acontecimento.

Pela manutenção do ethos dito, portanto, há uma informação que leva o leitor a construir um ethos de um sujeito preocupado em transmitir à população a tradição dos bons costumes da sociedade, do caminho que toda pessoa de "bem" deve seguir. O locutor procura, com isso, legitimar a sua posição política, bem como o partido no qual está afiliado, pela forma solidária com que se pretende seu discurso. Tenta-se, assim, apagar a imagem negativa que lhe foi produzida pela realização de tal manifestação.

\section{O ethos discursivo - mostrado}

Considera-se o ethos mostrado como propriamente o discursivo, pois é por esse plano, a partir de elementos inscritos na enunciação, que o destinatário constrói o ethos do locutor. Maingueneau (2010, p. 84) aponta alguns índices que são dados pela enunciação: "escolhas de ordem lexical, complexidade da sintaxe, ritmo das frases, jogos de planos enunciativos (parênteses, ironia, paródias...) etc.”.

Nesse sentido, podemos fazer uma hipótese, pelas escolhas de ordem lexical, tais como os vocábulos "alma", "tristeza", "lamentável", "sofro", "verdade", "respeito" e "humildemente", de que o locutor pretende criar uma cenografia de um gênero discursivo com um tom confessional, de forma bastante intimista. Os léxicos mobilizados não são comumente encontrados em textos de cunho político, no entanto, a cenografia, como uma espécie de diário confessional, procura estabelecer uma proximidade para com o destinatário, fazendo com que este construa um ethos de complacência da figura do governador.

Verifica-se, também, uma alternância dos embreantes de pessoa (MAINGUENEAU, 2013). Ora o locutor mobiliza a primeira pessoa do singular, ora mobiliza a primeira pessoa do plural. A articulação dessas vozes nos enunciados demonstra um jogo de polifonia. $\mathrm{O}$ uso da primeira pessoa do singular não está diretamente ligado à pessoa empírica do governador, mas, sim, a um locutor que pretende ser o responsável pelo enunciado.

No contexto político em que está inserida a figura de Beto Richa, qual é a voz que fala no fio discursivo? Na presença da primeira pessoa do singular, um locutor se responsabiliza pelo dito, mas, ao perceber as estratégias político-partidárias nas quais o governador está afiliado, nota-se uma outra voz que fala através desse eu posto na enunciação, a voz do partido PSBD. Dessa forma, podemos pensar na presença de um

\footnotetext{
7 Siglas referentes a "Partido da Social Democracia Brasileira", criado em 1988. Disponível em: $<$ http://www.psdb.org.br/psdb/historia/>.
} 
locutor preocupado com a situação em que se encontram os servidores estaduais, mas observa-se um enunciador (PSDB) preocupado em se defender das acusações políticas de outros partidos.

Em outros momentos da enunciação, a instância subjetiva faz uso do pronome possessivo nosso. No segmento discursivo "O nosso maior compromisso é com todos os paranaenses", é possível perceber, à medida que o discurso avança, que o enunciador procura redimensionar a responsabilidade do que é dito para uma extensão coletiva.

Podemos relacionar esse processo a uma tentativa do locutor de construir um ethos preocupado em difundir a responsabilidade do ocorrido no dia 29 de abril a todos os leitores, no caso, os paranaenses. Mas quem está na condição desses paranaenses? Quem está na condição de nosso na enunciação? Com esses questionamentos, podemos compreender uma das maneiras pela qual o locutor constrói, discursivamente, o ethos.

De uma forma, o destinatário é levado a construir um ethos de que o governo se sensibiliza e se preocupa em cuidar dos assuntos que envolvem o Estado do Paraná. Mas a não especificação do "maior compromisso", de certa maneira, procura isentar o governo desse compromisso: a preocupação com o povo paranaense. O dêitico nosso na cena enunciativa procura evidenciar não um posicionamento do locutor, mas um posicionamento partidário no qual a figura de Beto Richa está afiliada. Isso pode demonstrar uma defesa de interesses político-partidários do PSDB contra acusações de outros partidos de oposição.

No excerto "Vamos acreditar que as crises podem e devem ser superadas", o locutor faz uso também de um embreante de pessoa, mas, diferentemente da colocação do pronome possessivo nosso, o uso da locução verbal vamos acreditar carrega consigo uma situação hipotética de tempo futuro, no qual o locutor procura validar, por efeito dessa categoria de tempo indeterminado, o que se pretende na cena enunciativa: a superação de mais uma crise governamental.

Interessante destacar que os sentidos mobilizados pelas ocorrências, em sequência, dos verbos podem e devem implicam em sugerir ao destinatário uma espécie de conformidade pelo acontecimento. Pela memória discursiva ${ }^{8}$, o locutor procura reiterar aquilo que o brasileiro demonstra diante de crises governamentais: a superação de conflitos e a conformidade em aceitar as decisões do poder executivo de forma pacífica. Nesse sentido, o ethos que o locutor pretende construir é o de se apoiar em crises governamentais anteriores a fim de legitimar seu discurso.

Outras marcas linguísticas também funcionam para a mobilização do ethos discursivo. A referência ao uso do pronome você, em "Para que você tenha uma ideia", designa aquele leitor que está lendo o texto naquele momento. Se outro leitor lê esse "desabafo de Beto Richa", o referente de você muda, isto é, fazendo referência aos leitores de Beto Richa na plataforma Facebook, há uma variação quanto ao destinatário do texto. De um lado, se tivermos um leitor que se inscreve na mesma filiação ideológico-partidária da figura de Beto Richa, provavelmente este fará uma leitura complacente com o discurso do governador. De outro, caso tenhamos um leitor inscrito em outras formações discursivas, podemos pensar em um destinatário que se põe em contradição ideológica não somente à figura de Beto Richa, mas também ao partido que ele representa.

\footnotetext{
${ }^{8} \mathrm{Na}$ concepção de Courtine (2009), a noção de memória discursiva diz respeito à existência histórica do enunciado no seio de práticas discursivas, reguladas pelos aparelhos ideológicos.
} 
Podemos pensar também nesta escolha lexical como uma proposta de o locutor construir um ethos mais informal diante do seu leitor, já que o pronome você substitui o pronome $t u$ em situações de um discurso informal. Pelo aspecto de informalidade no discurso, o locutor procura construir um ethos de uma pessoa mais próxima da população, alguém que pretende esclarecer um problema complexo, de ordem política, com uma espécie de conversa informal. Com essa estratégia, o locutor implica uma tentativa de maior adesão de seu discurso.

Outro elemento importante para analisarmos o ethos discursivo da figura de Beto Richa está na alteridade explícita, marcada pelas aspas do enunciado "quanto pior, melhor". Como marca de heterogeneidade enunciativa mostrada (AUTHIER-REVUZ, (2004), as aspas funcionam como categorizadoras de um discurso-outro no discurso do eu. Conforme Maingueneau (1997), "as aspas designam a linha de demarcação que uma formação discursiva estabelece entre ela e seu exterior".

Desse modo, podemos perceber que o comentário inicial demonstra o lugar discursivo no qual o enunciador do texto se inscreve. Ele procura delimitar o espaço de atuação de seu discurso, contradizendo o que se coloca no texto aspado. Neste caso, "quanto pior, melhor", faz menção à fala da presidente Dilma Rousseff ${ }^{9}$. No pronunciamento da presidente, houve um apelo para que os partidos políticos de oposição não enfraquecessem o atual governo, pois pretendiam instaurar um clima de "quanto pior, melhor". Isto é, para os partidos de oposição, quanto pior ficar a situação do governo Dilma, mais insustentável é a permanência dela na presidência.

O locutor, ao demarcar esse discurso inserido em outro posicionamento discursivo, procura introduzir na enunciação vozes que validam o seu ethos, sustentado pelos valores comprometidos pela inscrição de sua formação discursiva. Com efeito, há uma ancoragem da instância subjetiva na proposta e desarticulação do que é dito por outros partidos de oposição.

O locutor, portanto, quando retoma, nessa conjuntura, o dito "Quanto pior, melhor", está preocupado em construir um ethos de um político que está em parceria com o governo federal, sem desavenças políticas. No entanto, o enunciador, ao retomar esse dizer, pretende fazer com que os eleitores da oposição sejam solidários a ele, implicando um apelo implícito do enunciador para que não tenha um índice alto de desaprovação do seu governo.

\section{Palavras finais}

Essa breve análise do texto publicado na fanpage de Beto Richa, que tratou, inicialmente, de ser uma espécie de desabafo com relação ao episódio do dia 29 de abril, implicou em demonstrar um modo de construção de um ethos da figura do governador Beto Richa preocupado com a situação política do atual partido governista (PSDB) frente às manifestações populares.

\footnotetext{
9 Pronunciamento da presidente Dilma Rousseff, em 14/08/2015, durante o lançamento de ações do Ministério da Cultura para a plataforma colaborativa Dialoga Brasil, em Salvador, BA. Informação retirada do site: <http://noticias.uol.com.br/politica/ultimas-noticias/2015/08/14/dilma-critica-clima-de-quantopior-melhor-nao-tem-compromisso-com-o-pais.htm>. Acesso em: 29 set. 2015.
} 
Foi possível verificar que houve uma tentativa da figura do governador em construir um ethos acentuado num posicionamento confessional, que procura demonstrar uma imagem do governador solidário e complacente com a situação dos servidores do Estado do Paraná. Esse ethos implicou uma defesa político-ideológica de Beto Richa pela situação em que ele se encontra no seu segundo mandato. $\mathrm{O}$ locutor, portanto, durante a enunciação, está preocupado em responsabilizar outras entidades, tais como o sindicato dos professores e os partidos de oposição.

\section{REFERÊNCIAS}

AMOSSY, R. (Org.). Imagens de Si no Discurso: a construção do ethos. 2. ed. São Paulo: Contexto, 2011.

AUTHIER-REVUZ, J. Entre a transparência e a opacidade: um estudo enunciativo do sentido. Porto Alegre: EDIPUCRS, 2004. p. 11-80.

BARONAS, R. L Ensaios em Análise do Discurso: questões analítico-teóricas. São Carlos: EdUFSCar, 2011.

CHARAUDEAU, P. Pathos e discurso político. In: MACHADO, I. L., MENEZES, W.; MENDES, E. (Org.). As Emoções no Discurso. v. 1. Rio de Janeiro: Lucerna, 2007. p. 240-251. Disponível em: <http://www.patrick-charaudeau.com/Pathos-e-discursopolitico.html>. Acesso em: 12 set. 2015.

COURTINE, J. J. Análise do discurso político: o discurso comunista endereçado aos cristãos. São Carlos: EdUSFSCar, 2009.

DUCROT, O. O dizer e o dito. Campinas: Pontes, 1987.

INSTITUTO BRASILEIRO DE GEOGRAFIA E ESTATÍSTICA (IBGE). Trabalho e rendimento. $2014 . \quad$ Disponível em: $<\mathrm{fttp}$ //ftp.ibge.gov.br/Trabalho_e_Rendimento/Pesquisa_Nacional_por_Amostra_de_D omicilios_continua/Trimestral/Microdados/Documentacao/Dicionario_e_input.zip>.

Acesso em: 12 set. 2015.

MAINGUENEAU, D. Novas tendências em Análise do Discurso. Tradução de Freda Indursky. 3. ed. Campinas: Pontes, 1997.

. Ethos, cenografia, incorporação. In: AMOSSY, R. (Org.). Imagens de si no discurso: a construção do ethos. São Paulo: Contexto, 2005.

. Análise de textos de comunicação. Tradução de Maria Cecília Perez de Souza-eSilva e Décio Rocha. 6. ed. São Paulo: Cortez, 2013.

Editorial, 2015.

Discurso e Análise do Discurso. Tradução de Sírio Possenti. São Paulo: Parábola

MAINGUENEAU, D.; POSSENTI, S.; SOUZA-E-SILVA, M. C. P. de (Org.). Cenas da enunciação. São Paulo: Parábola Editorial, 2008.

MAINGUENEAU, D.; POSSENTI, S.; SOUZA-E-SILVA, M. C. P. de (Org.). Doze conceitos em Análise do Discurso. Tradução de Adail Sobral et al. São Paulo: Parábola Editorial, 2010. 
SILVA, T. D. da. Sociedade da imagem, sociedade da informação e o sujeito. In: SILVA T. D. da; SOUZA, T. C. de; AGUSTINI, C. (Org.). Imagens na comunicação e discurso. São Paulo: Annablume; Belo Horizonte: FAPEMIG, 2012.

Recebido em: 27/08/2016

Aprovado em: 05/03/2017 